\title{
Correlation between Gut Microbiota, its Metabolic Products, and their Association with Liver Enzymes among Sample of Egyptian Females
}

\author{
Nayera E. Hassan ${ }^{1}$ (D), SaharA. El-Masry * (D), AyatNageeb ${ }^{1}$ (D) Mohamed S. El Hussieny $^{1}$ (D), Aya Khalil ${ }^{1}$ (D), Manal MouhamedAly ${ }^{1}$ (D), \\ Muhammad Al-Tohamy Soliman ${ }^{1}$ (D), Ahmed Ismail ${ }^{1}$, Gamila El-Saeed ${ }^{2}$ D, Adel Hashish ${ }^{3}$ (D) Mohamed Selim $^{4}$ (D) \\ ${ }^{1}$ Department of Biological Anthropology, Medical Research and Clinical Studies Institute, National Research Centre, Giza, \\ Egypt; ${ }^{2}$ Department of Medical Biochemistry, Medical Research and Clinical Studies Institute, National Research Centre, \\ Giza, Egypt; ${ }^{3}$ Department of Children with Special Needs, Medical Research and Clinical Studies Institute, National Research \\ Centre, Giza, Egypt; ${ }^{4}$ Department Researches and Applications of Complementary Medicine, Medical Research and Clinical \\ Studies Institute, National Research Centre, Giza, Egypt
}

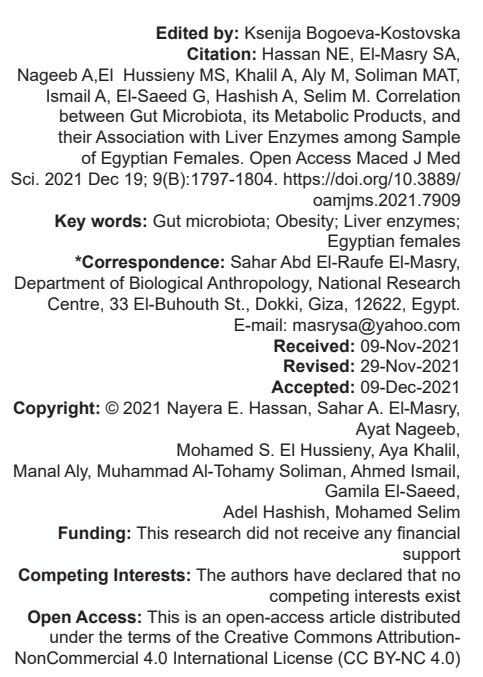

\begin{abstract}
BACKGROUND: Gut microbiota plays critical role in pathogenesis of obesity, liver metabolism and associated diseases.

AIM: The present study aimed to identify existing gut microbiota enterotypes and their metabolic products profiles and investigate correlation between gut microbiota; body mass index (BMI); and liver enzymes among sample of normal weight and obese Egyptian females.

METHODS: A case-control cross-sectional study included 112 Egyptian females; 82 obese and 30 normal weights aged 25-60 years. For each participant, anthropometric measurements (weight, height, and BMI), laboratory investigations (Aspartate amino transferase [AST], Alanine amino transferase [ALT], Short-chain fatty acids [SCFA], and C-reactive protein [CRP]) and microbiota analysis were done.

RESULTS: Obese females had higher significant values of CRP, AST, ALT, SCFA, log Bacteroidetes, Firmicutes, Firmicutes/Bacteroidetes ratio, and Lactobacillus. Among normal weight group, Lactobacillus had significant positive correlations with SCFA, Bifidobacteria, and Firmicutes, and significant negative correlations with AST, ALT, and CRP. While Bifidobacteria had significant negative correlations with height and ALT, Bacteroidetes bacteria had significant positive correlations with SCFA, and significant negative correlations with age and height, Firmicutes bacteria had significant negative correlations with AST and ALT, and Firmicutes/Bacteroidetes ratio had significant negative correlations with AST, ALT, and SCFA. Among obese group, Lactobacillus and Bifidobacteria had significant negative correlations with Firmicutes/Bacteroidetes ratio, and Firmicutes bacteria had significant negative correlations with
\end{abstract} ALT.

CONCLUSION: The beneficial Lactobacillus and Bifidobacteria have their good impact on improving obesity status and liver functions.

\section{Introduction}

Intestinal microbiota; the group of microorganisms inhabiting the gastrointestinal tract; plays a critical role in the host's immune system regulation, natural defense against infection, and nutrient metabolism [1]. Its dysbiosis has been linked to pathophysiology of obesity and its related metabolic disorders. Gut microbial changes have been involved in chronic low-grade "metabolic" inflammation whose metabolic products could trigger the development of insulin resistance in obesity and its complications [2]. Therefore, alterations in gut microbiota composition were thought as a primary cause of inflammation observed in obesity and type 2- diabetes [3].

Short-chain fatty acids (SCFAs) represent products of fermentation of dietary fibers by the anaerobic intestinal microbiota that has shown to exert several beneficial effects on energy metabolism [4]. It became apparent that SCFAs can play a part in inhibiting inflammatory processes and might have a key role in the prevention and treatment of the metabolic complications [5].

The abundance of microbiota responsible for fermenting carbohydrates leads to increased biosynthesis of SCFA, providing an extra source of energy for the host that is later stored as lipids or glucose and so contributing to the pathogenesis of obesity and its related metabolic disorders [6].

Gut microbiota has also shown to impact liver diseases through the modulation of host immune response and the production of inflammatory metabolites [7]. Specific strains of gut microbiota 
were identified in liver diseases with different causes, extending from steatohepatitis, fibrosis, cirrhosis, and reaching to hepatocellular carcinoma [8]. The previous studies suggested that liver enzymes showed high sensitivity to metabolic disorders, and that liver enzymes may provide a diagnostic tool for the metabolic complications [9], [10].

C-reactive protein (CRP) is an acute-phase reactant and an inflammatory marker that can be regulated through the effects of inflammatory metabolic products of specific gut microbes in cardiovascular disease, type 2-diabetes and obesity [11]. Serum concentrations of CRP were found to be elevated in overweight and obese individuals, therefore, obesity especially visceral obesity is currently considered as a low-grade inflammatory disease [12].

Thus, understanding the relationship between the gut microbiota and inflammation is essential in clinical practice because anti-inflammatory microbiota can be engaged in probiotic supplements for treating various metabolic disorders.

The present study aimed to identify the existing enterotypes of gut microbiota and its metabolic products profiles, and to investigate the correlation between gut microbiota and its metabolic products; body mass index (BMI) and liver enzymes among a sample of normal weight and obese Egyptian females.

\section{Subjects and Methods}

This is a case-control cross-sectional study, included a total of 112 Egyptian females; 82 obese females with age ranges from 25 up to 60 years with mean age $41.62 \pm 10.70$ years, in addition to 30 normal weight females within the same age range.

The study was carried out at the Medical Research Excellence Center (MERC), National Research Centre (NRC) as part of a cross-sectional survey of a project funded by NRC Egypt, 2019-2022 entitled "Gut Microbiota in Obesity and Metabolic syndrome among obese women: Interactions of the Microbiome, Epigenetic, Nutrition and Probiotic Intervention." (12 ${ }^{\text {th }}$ Research Plan of the NRC), which was approved from "Ethics Committee of NRC" (Approval no 19/236).

\section{Methods}

For each participated woman, anthropometric measurements, laboratory investigations, and microbiota analysis were done.

\section{Anthropometric measurements}

Body weight and height were measured, following the recommendations of the "International Biological Program" [13]. Body weight (Wt) was determined to the nearest $0.01 \mathrm{~kg}$ using a Seca Scale Balance, with the woman wearing minimal clothes and with no shoes. Body height $(\mathrm{Ht})$ was measured to the nearest $0.1 \mathrm{~cm}$ using a Holtain portable anthropometer. BMI was calculated (BMI: Weight [in kilograms] divided by height [in meters squared]). The participant females were classified according to their BMI into two groups: 30 females normal BMI $\left(\mathrm{BMl}=18-<25 \mathrm{~kg} / \mathrm{m}^{2}\right)$ and 82 obese females $\left(\mathrm{BMI} \geq 30 \mathrm{~kg} / \mathrm{m}^{2}\right)$.

\section{Blood sampling and laboratory investigations}

In the morning, venous blood samples were drawn from the participated females, using venipuncture. Biochemical parameters were performed on sera that were stored at $-70^{\circ} \mathrm{C}$ until used for assessment of short chain fatty acids (SCFA), CRP and liver enzymes: Aspartate amino transferase (AST) and Alanine amino transferase (ALT). All were done in the laboratory of "Medical Excellence Research Center MERC" which is a part of "NRC," Egypt.

Human short chain fatty acids (SCFA) were assessed in serum using Enzyme Linked Immunosorbent Assay (ELISA) kits; Catalog Number: MBS7269061 according to the method described by den Besten et al. [14].

The assay of CRP in serum was performed by ELISA kits, Cat No.: RAP002 [15]

Serum concentrations of AST and ALT were determined using the automated clinical chemistry analyzer Olympus $\mathrm{AU} 400$ analyzer. https://www. mybiosource.com.

\section{Microbiota analysis}

The proportion of Lactobacillus and Bifidobacteria; and Firmicutes/Bacteroidetes ratio strains were assessed in the stool of all participants using the real time polymerase chain reaction. Specimen collection and preparation: Stool was collected by defecation in a plain sterilized container allowed to be frozen. Specimen Storage and Preparation: Stool was frozen on at $-20^{\circ} \mathrm{C}$. The primers and probes were used to detect Bifidobacterium spp. and Lactobacillus spp; and Firmicutes spp. and Bacteroidetes spp., where based on 16S rRNA gene sequences retrieved from the National Center for biotechnology information databases by means of the entrez program [16]. Reagents provided by kits: DNA extraction Kit. Assay procedure: DNA extraction: The QIAamp DNA Stool Minikit (Qiagen) was used to extract DNA from $1 \mathrm{~g}$ of fresh or frozen stool sample according to the 
manufacturer's instructions. Bacterial quantification by real-time PCR was done.

\section{Statistical analysis}

Data were analyzed using the Statistical Package for the Social Sciences (SPSS/Windows version 18, SPSS Inc., Chicago, IL, USA). Normality of data was tested using the Kolmogorov-Smirnov test. The data were normally distributed. Hence, the parametric tests were used.

The 112 participated females were classified into two groups groups according to their BMI (30 normal weight and 82 obese). The parametric data were expressed as mean \pm SD. The various parametric variables of the different groups were analyzed and compared using independent t test. Pearson's correlation test was used to assess the relations between each enterotypes of microbiota and patient's anthropometric and laboratory parameters among the two groups. $\mathrm{P}<0.05$ was regarded as statistically significant for all tests.

\section{Results}

Comparisons between the anthropometric measurements, laboratory and microbiota data in the two groups; normal weight and obese; are illustrated in Table 1. There were highly significant differences in body weight and BMI, where the obese females had the higher values. In respect to the laboratory investigations and microbiota, obese females had the higher highly significant values of CRP and higher significant values of AST, ALT, and SCFA. In addition, obese females had insignificant higher values of log bacteroid, Firmicutes, Firmicutes/ bacteroid ratio, and Lactobacillus, and insignificant lower values of log Bifidobacteria than normal weight females. Among obese females, the insignificant increase in log

Table 1: Comparisons between the normal weight and obese groups regarding anthropometry, laboratory investigations for gut microbiota, and its metabolic products

\begin{tabular}{|c|c|c|c|c|c|c|}
\hline \multirow[t]{2}{*}{ Variables } & \multicolumn{2}{|c|}{$\begin{array}{l}\text { Normal weight } \\
\text { group }(n=30)\end{array}$} & \multicolumn{2}{|c|}{$\begin{array}{l}\text { Obese group } \\
(n=82)\end{array}$} & \multirow[t]{2}{*}{$\mathrm{t}$} & \multirow[t]{2}{*}{$\mathrm{p}$} \\
\hline & Mean & $+S D$ & Mean & $+S D$ & & \\
\hline Age (years) & 32.40 & 7.79 & 44.80 & 9.51 & -6.467 & $0.000^{* *}$ \\
\hline \multicolumn{7}{|l|}{ Anthropometry } \\
\hline Weight (kg) & 49.04 & 5.80 & 94.14 & 17.80 & -20.192 & $0.000^{* *}$ \\
\hline Height $(\mathrm{cm})$ & 158.12 & 5.62 & 158.69 & 6.27 & -0.437 & 0.663 \\
\hline $\mathrm{BMI}\left(\mathrm{kg} / \mathrm{m}^{2}\right)$ & 19.56 & 1.45 & 37.26 & 5.93 & -25.058 & $0.000^{* *}$ \\
\hline \multicolumn{7}{|l|}{ Lab } \\
\hline $\operatorname{ALT}(\mathrm{U} / \mathrm{L})$ & 15.10 & 8.218 & 19.74 & 8.300 & -2.598 & $0.011^{*}$ \\
\hline AST (U/L) & 19.00 & 5.246 & 22.45 & 6.626 & -2.549 & $0.012^{*}$ \\
\hline SCFA $((\mu \mathrm{mol} / \mathrm{L})$ & 10.35 & 9.56 & 15.64 & 15.93 & -2.094 & $0.039^{*}$ \\
\hline $\mathrm{CRP}(\mathrm{ng} / \mathrm{ml})$ & 3576.00 & 3439.46 & 7143.16 & 2669.75 & -5.695 & $0.000^{* *}$ \\
\hline \multicolumn{7}{|l|}{ Microbiota } \\
\hline Log Lactobacillus & 5.92 & & 6.08 & & -1.392 & 0.167 \\
\hline Log Bifidobacteria & 7.21 & 2.60 & 6.44 & 1.60 & 1.521 & 0.137 \\
\hline Log Bacteroid & 12.75 & 1.37 & 13.15 & 1.33 & -1.784 & 0.079 \\
\hline Log Firmicutes & 8.95 & 1.02 & 9.24 & 1.49 & -0.896 & 0.372 \\
\hline Log Firmicutes/ & 0.70 & 0.11 & 0.71 & 0.13 & -0.204 & 0.839 \\
\hline Bacteroid ratio & & & & & & \\
\hline
\end{tabular}

Open Access Maced J Med Sci. 2021 Dec 19; 9(B):1797-1804.
Bacteroidetes was more than the insignificant increase in log Firmicutes, this leads to insignificant minor increase in log Firmicutes/Bacteroidetes ratio.

Pearson's correlations between each enterotypes of microbiota and their metabolic products among normal weight and obese females are presented in Tables 2-3. Lactobacillus had significant positive correlations with Bacteroidetes bacteria among the two groups (normal and obese), and significant negative correlations with Firmicutes/Bacteroidetes ratio among obese group. Among normal weight group (Table 2), Lactobacillus had significant positive correlations with SCFA, Bifidobacteria, and Firmicutes, and significant negative correlations with AST, ALT, and CRP.

Bifidobacteria had significant positive correlations with Lactobacillus among normal weight group, and had significant positive correlations with Bacteroidetes bacteria and significant negative correlations with Firmicutes/Bacteroidetes ratio among the obese group (Table 3). Among normal weight group, Bifidobacteria had significant negative correlations with $\mathrm{Ht}$ and ALT.

Bacteroidetes bacteria had significant positive correlations with Lactobacillus and significant negative correlations with Firmicutes/Bacteroidetes ratio among the two groups (normal and obese), and significant positive correlations with Bifidobacteria among the obese group only. Among normal weight group, Bacteroidetes bacteria had significant positive correlations with SCFA, and significant negative correlations with age and height.

Firmicutes had significant positive correlations with Firmicutes/Bacteroidetes ratio among the 2 groups (normal, obese). Among normal weight group, Firmicutes bacteria had significant negative correlations with ALT and AST. Among obese group, Firmicutes bacteria had significant negative correlations with ALT.

Firmicutes/Bacteroidetes ratio had significant positive correlation with Firmicutes and significant negative correlations with Bacteroidetes among the two groups (normal and obese). It had significant negative correlations with Lactobacillus and Bifidobacterium among obese group. Among normal weight group, Firmicutes/Bacteroidetes ratio had significant negative correlations with ALT, AST, and SCFA.

While among obese females, there were insignificant correlations between any type of studied microbiota and any of the anthropometric or laboratory parameters; except Firmicutes bacteria had significant negative correlations with ALT.

\section{Discussion}

The human gut harbors a large population of microorganisms, the gut microbiota, which exerts 
Table 2: Pearson's correlations between each enterotypes of microbiota and its metabolic products among normal weight females

\begin{tabular}{|c|c|c|c|c|c|c|c|c|c|c|}
\hline \multirow[t]{2}{*}{ Variables } & \multicolumn{2}{|c|}{ Log Lactobacillus } & \multicolumn{2}{|c|}{ Log Bifido } & \multicolumn{2}{|c|}{ Log Bacteroid } & \multicolumn{2}{|c|}{ Log Firmicutes } & \multicolumn{2}{|c|}{$\begin{array}{l}\text { Log Firmicutes/ } \\
\text { Bacteroid ratio }\end{array}$} \\
\hline & $\mathrm{r}$ & $\mathrm{p}$ & $r$ & $\mathrm{p}$ & $r$ & $\mathrm{p}$ & $\mathrm{r}$ & $\mathrm{p}$ & $\mathrm{r}$ & $\mathrm{p}$ \\
\hline Age (years) & -0.243 & 0.195 & -0.285 & 0.126 & -0.338 & $0.034^{*}$ & 0.037 & 0.845 & 0.211 & 0.263 \\
\hline \multicolumn{11}{|l|}{ Anthropometry } \\
\hline Weight (kg) & -0.078 & 0.683 & -0.044 & 0.817 & -0.350 & 0.058 & -0.021 & 0.914 & 0.139 & 0.463 \\
\hline Height $(\mathrm{cm})$ & -0.325 & 0.080 & -0.400 & $0.029^{*}$ & -0.575 & $0.001^{* *}$ & -0.150 & 0.430 & 0.130 & 0.495 \\
\hline BMI $\left(\mathrm{kg} / \mathrm{m}^{2}\right)$ & 0.167 & 0.379 & 0.341 & 0.065 & -0.023 & 0.902 & 0.105 & 0.580 & 0.101 & 0.595 \\
\hline \multicolumn{11}{|l|}{ Lab } \\
\hline ALT (U/L) & -0.555 & $0.001^{\star *}$ & -0.387 & $0.035^{*}$ & 0.297 & 0.110 & -0.713 & $0.000^{\star *}$ & -0.687 & $0.000^{\star \star}$ \\
\hline AST (U/L) & -0.587 & $0.001^{* *}$ & -0.168 & 0.376 & 0.328 & 0.077 & -0.683 & $0.000^{\star *}$ & -0.689 & $0.000^{\star *}$ \\
\hline SCFA $((\mu \mathrm{mol} / \mathrm{L})$ & 0.408 & $0.025^{*}$ & -0.231 & 0.220 & 0.460 & $0.011^{*}$ & -0.266 & 0.155 & -0.387 & $0.035^{\star}$ \\
\hline CRP (ng/ml) & -0.417 & $0.022^{*}$ & -0.074 & 0.699 & -0.220 & 0.243 & -0.253 & 0.178 & -0.092 & 0.629 \\
\hline \multicolumn{11}{|l|}{ Microbiota } \\
\hline Log Lactobasillus & & & 0.361 & $0.050^{*}$ & 0.394 & $0.031^{*}$ & 0.373 & $0.042^{*}$ & 0.106 & 0.576 \\
\hline Log bifido & 0.361 & $0.050^{*}$ & & & 0.272 & 0.147 & 0.120 & 0.529 & -0.019 & 0.919 \\
\hline Log bacteroid & 0.394 & $0.031^{*}$ & 0.272 & 0.147 & & & -0.320 & 0.085 & -0.694 & $0.000^{\star \star}$ \\
\hline Log Firmicutes & 0.373 & $0.042^{*}$ & 0.120 & 0.529 & -0.388 & 0.085 & & & 0.902 & $0.000^{\star \star}$ \\
\hline Log Firmicutes/Bacteroid ratio & 0.106 & 0.576 & -0.019 & 0.919 & -0.694 & $0.000^{\star *}$ & 0.902 & $0.000^{\star *}$ & & \\
\hline
\end{tabular}

N.B. ${ }^{* *} p<0.01$ =highly significant differences. ${ }^{*} p<0.05$-significant difference. ALT: Alanine aminotransferase, AST: Aspartate aminotransferase.

a notable influence on the host in modulating energy balance (host metabolism and energy uptake [17].

The gut microbiota appears to play a role in the pathogenesis of obesity and associated diseases [18] This community can contribute to the development of obesity primarily by influencing dietary energy intake and intestinal absorption of nutrients [19], but it can also provide the human host with benefits besides energy extraction, including a reduction of low grade chronic inflammation associated with obesity and metabolic complications [1].

The present results showed that Bacteroides bacteria were the most prevalent type among the studied microbiota, followed by the gut microbes Firmicutes, followed by the two beneficial types the Lactobacillus and Bifidobacteria. Comparisons between the normal weight and obese groups revealed that obese females had insignificant higher values of log bacteroid, Firmicutes, Firmicutes/bacteroid ratio, than normal weight females. Similarly, studies in France [20] and in Brazil [21] showed that Bacteroides are one of the most abundant bacteria in the human gut and its dysbiosis was strongly linked to insulin resistance, altered metabolism, and obesity.

Among obese females, the insignificant increase in bacteroid was more than the insignificant increase in Firmicutes, this leads to insignificant difference in Firmicutes/bacteroid ratio between obese and control groups. The insignificant differences in statistical analysis of the microbiota might be related to the use of the log values.

Studies have reported controversial data about the Firmicutes/Bacteroidetes ratio and the proportion of Firmicutes and Bacteroidetes in obesity. The present data were in agreement with many other studies in China [22], United Kingdom [23], and Canada [24] where insignificant differences in Firmicutes to Bacteroidetes ratio was observed between lean and obese individuals, other studies found that the gut microbiota of obese people is characterized by an increase in the Firmicutes/Bacteroidetes ratio; as in Ukraine [25] and Italy [26]; while others even find an opposite relationship; as in China [27].

Difference in microbiota composition can be related to regional, environmental, or dietary causes. It could also be due to the insufficient number of subjects included in some studies, making their statistical power insufficient to detect small variations. Therefore, changes in microbiota composition from one population to another should not be generalized [28].

Obese females in the present study had insignificant higher values of log Lactobacillus, and insignificant lower values of Bifidobacteria; than normal weight ones. Similarly, a study showed that microbiota

Table 3: Pearson's correlations between each enterotypes of microbiota and patient's clinical and metabolic parameters among total obese females

\begin{tabular}{|c|c|c|c|c|c|c|c|c|c|c|}
\hline \multirow[t]{2}{*}{ Variables } & \multicolumn{2}{|c|}{ Log Lactobacillus } & \multicolumn{2}{|c|}{ Log Bifido } & \multicolumn{2}{|c|}{ Log Bacteroid } & \multicolumn{2}{|c|}{ Log Firmicutes } & \multicolumn{2}{|c|}{$\begin{array}{l}\text { Log Firmicutes/ } \\
\text { Bacteroid ratio }\end{array}$} \\
\hline & $r$ & $p$ & $r$ & $\mathrm{p}$ & $r$ & $p$ & $r$ & $p$ & $r$ & $p$ \\
\hline Age (years) & 0.056 & 0.622 & -0.051 & 0.652 & 0.166 & 0.138 & -0.066 & 0.559 & -0.154 & 0.171 \\
\hline \multicolumn{11}{|l|}{ Anthropometry } \\
\hline Weight (kg) & 0.120 & 0.284 & -0.036 & 0.747 & 0.077 & 0.494 & -0.048 & 0.672 & -0.093 & 0.410 \\
\hline Height $(\mathrm{cm})$ & -0.043 & 0.705 & -0.044 & 0.698 & -0.050 & 0.654 & -0.083 & 0.459 & -0.046 & 0.571 \\
\hline BMI $\left(\mathrm{kg} / \mathrm{m}^{2}\right)$ & 0.160 & 0.153 & -0.014 & 0.903 & 0.115 & 0.306 & -0.010 & 0.927 & -0.074 & 0.514 \\
\hline \multicolumn{11}{|l|}{ Lab } \\
\hline $\operatorname{ALT}(\mathrm{U} / \mathrm{L})$ & -0.184 & 0.115 & 0.028 & 0.812 & -0.107 & 0.360 & -0.249 & $0.031^{*}$ & -0.137 & 0.241 \\
\hline AST (U/L) & -0.064 & 0.587 & -0.082 & 0.484 & 0.045 & 0.701 & -0.052 & 0.660 & -0.059 & 0.616 \\
\hline SCFA $((\mu \mathrm{mol} / \mathrm{L})$ & 0.158 & 0.176 & 0.098 & 0.402 & -0.033 & 0.779 & -0.183 & 0.116 & -0.129 & 0.268 \\
\hline $\mathrm{CRP}(\mathrm{ng} / \mathrm{ml})$ & -0.013 & 0.912 & -0.068 & 0.562 & -0.121 & 0.300 & 0.105 & 0.368 & 0.143 & 0.221 \\
\hline \multicolumn{11}{|l|}{ Microbiota } \\
\hline Log Lactobasillus & & & 0.054 & 0.631 & 0.619 & $0.000^{* *}$ & 0.038 & 0.733 & -0.304 & $0.006^{* *}$ \\
\hline Log bifido & 0.054 & 0.631 & & & 0.503 & $0.000^{* *}$ & 0.020 & 0.859 & -0.249 & $0.025^{\star}$ \\
\hline Log bacteroid & 0.619 & $0.000^{* *}$ & 0.503 & $0.000^{* *}$ & & & 0.129 & 0.250 & -0.432 & $0.000^{\star *}$ \\
\hline Log Firmicutes & 0.038 & 0.733 & 0.020 & 0.859 & 0.129 & 0.250 & & & 0.831 & $0.000^{* *}$ \\
\hline Log Firmicutes/Bacteroid ratio & -0.304 & $0.006^{* *}$ & -0.249 & $0.025^{\star}$ & -0.432 & $0.000^{* *}$ & 0.831 & $0.000^{* *}$ & & \\
\hline
\end{tabular}


composition of overweight and obese adults with dyslipideamia in China was characterized by over representation of Lactobacillus as a counter protective reaction but with reduction of Bifidobacterium [22]. It was also found that gut microflora in obese patients is characterized by greater numbers of Lactobacillus and lesser numbers of Bifidobacteria species [29].

Similarly, Long et al. found that Bifidobacterium was less abundant among obese African American individuals compared with normal-weight ones [30]. Moreover, Collado et al. [31] found a protective effect of high concentration of Bifidobacterium against obesity during infancy and adulthood. Bifidobacteria may decrease fat absorption through the deconjugation of bile acids [32], which are possibly related to its reduction in obese subjects. A study indicates that in mice on a high-fat diet, ingestion of sterilized Bifidobacteria suppressed fat accumulation, improved insulin resistance, and lowered blood glucose levels [33].

Among obese females, Firmicutes/ Bacteroidetes ratio had significant negative correlation with Lactobacillus and Bifidobacterium. Confirming the present results, the genera Lactobacillus probiotic was found to have the potential to reduce the Firmicutes/ Bacteroidetes ratio and obesity as the administration of Lactobacillus decreased the Firmicutes/Bacteroidetes ratio in obese mice and reduced fatty acid synthesis, in the liver [34]. In another study, Lactobacillus consumed with a high-fat diet prevented weight gain and decreased the Firmicutes/Bacteroidetes ratio [35].

The most abundant metabolic products of gut microbiota are short-chain fatty acids (SCFAs), mainly acetate, propionate, and butyrate, which are produced by anaerobic fermentation of undigested carbohydrates [36]. SCFAs play a crucial role in the development of obesity as they interact with adipose tissue promoting adipocytes formation and inhibiting lipolysis [37]. In addition, SCFAs decrease the synthesis of the hunger-suppressing hormones leptin, peptide $Y Y$, and glucagon-like peptide 1 [38].

Inthe presentstudy, SCFAhadsignificantpositive correlations with Lactobacillus and Bacteroidetes, in addition to significant negative correlation with Firmicutes/Bacteroidetes ratio among only normal weight group. These results could be related to the fact that acetate and propionate are mainly produced by the phylum Bacteroidetes, whereas butyrate is the predominant product of the phylum Firmicutes [14]. Studies also showed that acetate appears to be predominantly obesogenic, whereas butyrate and propionate are mainly anti-obesogenic [39].

These results confirm the beneficial effect of probiotic microorganisms as Lactobacillus on the balance of the intestinal microbiome and produced metabolites, including SCFAs as Lactobacillus showed the ability to increase in response to the concomitant rise in obesogenic acetate producing bacteria, that is, Bacteroidetes.
Age had significant negative correlation with Bacteroidetes among normal group. Ageing has been suggested to cause changes in the intestinal microbial community. Similar to the present results, the identified microbiome pattern of healthy ageing is characterized by depletion of Bacteroides, while retaining a high Bacteroides dominance into older age due to dysbiosis of obesity, and predicts decreased survival in a 4-year follow-up [40].

Concerning the laboratory investigations; among normal weight group; ALT and AST had significant negative correlation with Lactobacillus, Firmicutes and Firmicutes/Bacteroidetes ratio, while ALT only had significant negative correlation with Bifidobacteria. These correlations became insignificant among the obese group; except the significant negative correlation between ALT and Firmicutes which persist.

The gut microbiome appears to play a critical role in liver metabolism in healthy individuals as the present results showed that the decrease in the beneficial Lactobacillus and Bifidobacteria can be related to the increase in liver enzymes [41]. Many studies showed the efficacy of probiotic supplementation in liver diseases [42], [43]. The protective role of Lactobacillus and Bifidobacteria was insignificant among obese group in the present study, which could be due to intestinal dysbiosis.

Serum CRP is a marker of systemic inflammation, which is elevated in the presence of chronic conditions including obesity, type 2-diabetes, and several components of the metabolic syndrome [44].

In the present study, CRP had significant negative correlation with Lactobacillus among only normal weight group. Similarly, a study showed that high CRP levels were associated with decreased abundance of Lactobacillus and Bifidobacterium, and with increased abundance of Bacteroides [45]. Indeed a meta-analysis of 20 studies suggests that probiotic administration may significantly reduce serum CRP by reducing mucosal inflammation through modulation of cytokine levels and other inflammatory mediators [46].

\section{Conclusion}

Among obese group, Lactobacillus and Bifidobacteria had significant negative correlations with Firmicutes/Bacteroidetes ratio; however; these correlations were insignificant among normal weight group. Moreover, there were insignificant correlations between any type of studied microbiota and any of the anthropometric or laboratory parameters; except Firmicutes bacteria had significant negative correlations with ALT. 
Among normal weight non-obese group, ALT had significant negative correlations with Lactobacillus, Bifidobacteria, Firmicutes and Firmicutes / Bacteroidetes Ratio; this correlation persists only with Firmicutes among obese group; while AST had significant negative correlations with Lactobacillus, Firmicutes and Firmicutes / Bacteroidetes Ratio among normal weight non-obese group only. SCFA had significant positive correlations with Lactobacillus and Bacteroidetes, and significant negative correlation with Firmicutes / Bacteroidetes Ratio, while CRP had significant negative correlations with Lactobacillus only.

The beneficial Lactobacillus and Bifidobacteria have their good impact on improving obesity status and liver functions.

\section{Acknowledgments}

We would like to acknowledge our institute "National Research Centre"; Egypt; without their support this study could not be done. Authors are also grateful to everybody participated in this study; the employers of our institute who were the participants of this study, the technicians who helped in the laboratory analysis and the doctors who participated in collection of the data. Without their help, this study could not have been completed.

\section{Author Contribution}

NayeraE.Hassanconceivedanddesignedthestudy; she is the PI of the project from which this data were derived. Sahar A. El-Masry; statistical analysis and interpretation of the data, she is the Co-PI of the project from which this data were derived. Gamila SM El-Saeed; responsible about the laboratory investigations, Adel F. Hashish; responsible about themicrobiota analysis, Ayat N. Kamal; wrote the draft of the article, Mohamed S. El Hussieny, Aya Khalil, and Manal Mouhamed Aly; supervision on collection of data and references. Mohamed Selim, Mahmoud A.S. Afify, and Ahmed Saied Ismaeil; collected the data. All authors contributed to the collection of references, drafting of the article, and final approval of the version to be submitted. All the authors have accepted responsibility for the entire content of this submitted manuscript and approved submission.

\section{References}

1. Scheithauer TP, Rampanelli E, Nieuwdorp M, Vallance BA, Verchere $\mathrm{CB}$, van Raalte $\mathrm{DH}$, et al. Gut microbiota as a trigger for metabolic inflammation in obesity and Type 2 diabetes. Front Immunol. 2020;11:571731. https://doi.org/10.3389/ fimmu.2020.571731

PMid:33178196

2. Khan MJ, Gerasimidis K, Edwards CA, Shaikh MG. Role of gut microbiota in the aetiology of obesity: Proposed mechanisms and review of the literature. J Obes. 2016;2016:7353642. https://doi.org/10.1155/2016/7353642

PMid:27703805

3. Thaiss CA, Zmora N, Levy M, Elinav E. Themicrobiome and innate immunity. Nature. 2016;535(7610):65-74. https://doi. org/10.1038/nature18847

PMid:27383981

4. Canfora EE, Jocken JW, Blaak EE. Short-chain fatty acids in control of body weight and insulin sensitivity. Nat Rev Endocrinol. 2015;11(10):577-91. https://doi.org/10.1038/nrendo.2015.128 PMid:26260141

5. Hu GX, Chen GR, Xu H, Ge RS, Lin J. Activation of the AMP activated protein kinase by short-chain fatty acids is the main mechanism underlying the beneficial effect of a high fiber diet on the metabolic syndrome. Med Hypotheses. 2010;74(1):123-6. https://doi.org/10.1016/j.mehy.2009.07.022

PMid:19665312

6. Muscogiuri G, Cantone E, Cassarano S, Tuccinardi D, Barrea L, Savastano S, et al. Gut microbiota: A new path to treat obesity. Int J Obes Suppl. 2019;9(1):10-9. https://doi.org/10.1038/ s41367-019-0011-7

PMid:31391921

7. Hoyles L, Fernández-Real JM, Federici M, Serino $M$, Abbott J, Charpentier J, et al. Molecular phenomics and metagenomics of hepatic steatosis in non-diabetic obese women. Nat Med. 2018;24(7):1070-80. https://doi.org/10.1038/ s41591-018-0061-3. PMid:29942096

8. LiR, MaoZ, YeX, ZuoT. Humangutmicrobiomeand liverdiseases: From correlation to causation. Microorganisms. 2021;9(5):1017. https://doi.org/10.3390/microorganisms9051017 PMid:34066850

9. Steinvil A, Shapira I, Ben-Bassat OK, Cohen M, Vered $Y$ Berliner $S$, et al. The association of higher levels of withinnormal-limits liver enzymes and the prevalence of the metabolic syndrome. Cardiovasc Diabetol. 2010;9:30. https://doi. org/10.1186/1475-2840-9-30

PMid:20633271

10. Mostafa SA, Khunti K, Morris DH, Webb D, Srinivasan BT, Davies MJ. Can liver enzymes predict progression from prediabetes to Type 2 diabetes independent of factors associated with the metabolic syndrome in white Europeans and South Asians? Diabetologia. 2012;55:S135.

11. Noronha JA, Medeiros CC, Ada SC, Gonzaga NC, Ramos AT, Ramos AL. C-reactive protein and its relation to high blood pressure in overweight or obese children and adolescents. Rev Paul Pediatr. 2013;31(3):331-7. https://doi.org/10.1590/ S0103-05822013000300009

PMid:24142315

12. Faam B, Zarkesh M, Daneshpour MS, Azizi F, Hedayati M. The association between inflammatory markers and obesity-related factors in Tehranian adults: Tehran lipid and glucose study. Iran J Basic Med Sci. 2014;17(8):577-82. PMid:25422750

13. Hiernaux J, Tanner J. Growth and physical studies. In: Weiner JS, Lourie SA, editors. Human Biology: A Guide to Field Methods. United Kingdom: Blackwell Scientific Publications; 1969.

14. Den Besten G, van Eunen K, Groen AK, Venema K, Reijngoud DJ, Bakker BM. The role of short-chain fatty acids 
in the interplay between diet, gut microbiota, and host energy metabolism. J Lipid Res. 2013;54(9):2325-40. https://doi. org/10.1194/jlr.R036012

PMid:23821742

15. Mitra B, Panja M. High sensitive C-reactive protein: A novel biochemical markers and its role in coronary artery disease. J Assoc Physicians India. 2005;53:25-32.

PMid:15857009

16. Wheeler HE, Shah KP, Brenner J, Garcia T, Aquino-Michaels K, GTEx Consortium, et al. Survey of the heritability and sparse architecture of gene expression traits across human tissues. PLoS Genet. 2016;12(11):e1006423. https://doi.org/10.1371/ journal.pgen.1006423 PMid:27835642

17. Leung C, Rivera L, Furness JB, Angus PW. The role of the gut microbiota in NAFLD. Nat Rev Gastroenterol Hepatol. 2016;13(7):412-25. https://doi.org/10.1038/nrgastro.2016.85 PMid:27273168

18. Aoun A, Darwish F, Hamod N. The influence of the gut microbiome on obesity in adults and the role of probiotics, prebiotics, and synbiotics for weight loss. Prev Nutr Food Sci. 2020;25(2):113-23. https://doi.org/10.3746/pnf.2020.25.2.113 PMid:32676461

19. Dao MC, Clément K. Gut microbiota and obesity: Concepts relevant to clinical care. Eur J Intern Med. 2018;48:18-24. https://doi.org/10.1016/j.ejim.2017.10.005

PMid:29110901

20. Aron-Wisnewsky J, Prifti E, Belda E, Ichou F, Kayser BD, Dao MC, et al. Major microbiota dysbiosis in severe obesity: Fate after bariatric surgery. Gut. 2018;68(1):70-82. https://doi. org/10.1136/gutjnl-2018-316103 PMid:29899081

21. Ignacio A, Fernandes MR, Rodrigues VA, Groppo FC, Cardoso AL, Avila-Campos MJ, et al. Correlation between body mass index and faecalmicrobiota from children. Clin Microbiol Infect. 2016;22(3):258.e1-8. https://doi.org/10.1016/j. cmi.2015.10.031 PMid:26551842

22. Jin J, Cheng R, Ren Y, Shen X, Wang J, Xue Y, et al. Distinctive gut microbiota in patients with overweight and obesity with dyslipidemia and its responses to long-term orlistat and ezetimibe intervention: A randomized controlled open-label trial. Front Pharmacol. 2021;12:732541. https://doi.org/10.3389/ fphar.2021.732541

PMid:34512358

23. Duncan SH, Lobley GE, Holtrop G, Ince J, Johnstone AM, Louis $\mathrm{P}$, et al. Human colonic microbiota associated with diet, obesity and weight loss. Int J Obes (Lond). 2008;32(11):1720-4. https://doi.org/10.1038/ijo.2008.155

PMid:18779823

24. Fernandes J, Su W, Rahat-Rozenbloom S, Wolever TM, Comelli EM. Adiposity, gut microbiota and faecal short chain fatty acids are linked in adult humans. Nutr Diabetes. 2014;4(6):e121. https://doi.org/10.1038/nutd.2014.23 PMid:24979150

25. Koliada A, Syzenko G, Moseiko V, Budovska L, Puchkov K, Perederiy V, Gavalko Y, Dorofeyev A, Romanenko M, Tkach S, Sineok L, Lushchak O, Vaiserman A. Association between body mass index and Firmicutes/Bacteroidetes ratio in an adult Ukrainian population. BMC Microbiol. 2017;17(1):120. https:// doi.org/10.1186/s12866-017-1027-1

PMid:28532414

26. Palmas, V., Pisanu, S., Madau, V., Casula E, Deledda A, Cusano R, et al. Gut microbiota markers associated with obesity and overweight in Italian adults. Sci Rep. 2021;11(1):5532. https://doi.org/10.1038/s41598-021-84928-w

PMid:33750881

27. Duan $M$, Wang $Y$, Zhang $Q$, Zou $R$, Guo $M$, Zheng $H$. Characteristics of gut microbiota in people with obesity. PLoS One. 2021;16(8):e0255446. https://doi.org/10.1371/journal. pone. 0255446

PMid:34375351

28. Magne F, Gotteland M, Gauthier L, Zazueta A, Pesoa S, Navarrete $\mathrm{P}$, et al. The Firmicutes/Bacteroidetes ratio: A relevant marker of gut dysbiosis in obese patients? Nutrients. 2020;12(5):1474. https://doi.org/10.3390/nu12051474 PMid:32438689

29. Lê KA, Li Y, Xu X, Yang W, Liu T, Zhao X, et al. Alterations in fecal Lactobacillus and Bifidobacterium species in Type 2 diabetic patients in Southern China population. Front Physiol. 2013;3:496. https://doi.org/10.3389/fphys.2012.00496 PMid:23386831

30. Long J, Cai Q, Steinwandel M, Hargreaves MK, Bordenstein SR, Blot WJ, et al. Association of oral microbiome with Type 2 diabetes risk. J Periodontal Res. 2017;52(3):636-43. https://doi. org/10.1111/jre.12432

PMid:28177125

31. Collado MC, Isolauri E, Laitinen K, Salminen S. Effect of mother's weight on infant's microbiota acquisition, composition, and activity during early infancy: A prospective follow-up study initiated in early pregnancy. Am J Clin Nutr. 2010;92(5):1023-30. https://doi.org/10.3945/ajcn.2010.2987

PMid:20844065

32. Begley M, Hill C, Gahan CG. Bile salt hydrolase activity in probiotics. Appl Environ Microbiol. 2006;72(3):1729-38. https:// doi.org/10.1128/AEM.72.3.1729-1738.2006 PMid: 16517616

33. Kikuchi K, Ben Othman M, Sakamoto K. Sterilized Bifidobacteria suppressed fat accumulation and blood glucose level. Biochem Biophys Res Commun. 2018;501(4):1041-7. https://doi. org/10.1016/j.bbrc.2018.05.105 PMid:29777696

34. Ji YS, Kim HN, Park HJ, Lee JE, Yeo SY, Yang JS, et al. Modulation of the murine microbiome with a concomitant antiobesity effect by Lactobacillus rhamnosus GG and Lactobacillus sakei NR28. Benef Microbes. 2012;3(1):13-22. https://doi. org/10.3920/BM2011.0046 PMid:22348905

35. Ji Y, Park S, Park H, Hwang E, Shin H, Pot B, et al. Modulation of Active Gut Microbiota by Lactobacillus rhamnosus GG in a diet induced obesity murine model. Front Microbiol. 2018;9:710. https://doi.org/10.3389/fmicb.2018.00710 PMid:29692770

36. Rowland I, Gibson G, Heinken A, Scott K, Swann J, Thiele I, et al. Gut microbiota functions: Metabolism of nutrients and other food components. Eur J Nutr. 2018;57(1):1-24. https://doi. org/10.1007/s00394-017-1445-8 PMid:28393285

37. Kimura I, Ozawa K, Inoue D, Imamura T, Kimura K, Maeda T, et al. The gut microbiota suppresses insulin-mediated fat accumulation via the short-chain fatty acid receptor GPR43. Nat Commun. 2013;4:1829. https://doi.org/10.1038/ncomms2852 PMid:23652017

38. Tseng $\mathrm{CH}, \mathrm{Wu} \mathrm{CY}$. The gut microbiome in obesity. J Formos Med Assoc. 2019;118 Suppl 1:S3-9. https://doi.org/10.1016/j. jfma.2018.07.009 PMid:30057153

39. Shoaie S, Karlsson F, Mardinoglu A, Nookaew I, Bordel S, Nielsen J. Understanding the interactions between bacteria in the 
human gut through metabolic modeling. Sci Rep. 2013;3:2532. https://doi.org/10.1038/srep02532

PMid:23982459

40. Wilmanski T, Diener C, Rappaport N, Patwardhan S, Wiedrick J, Lapidus $\mathrm{J}$, et al. Gut microbiome pattern reflects healthy ageing and predicts survival in humans. Nat Metab. 2021;3(2):274-86. https://doi.org/10.1038/s42255-021-00348-0

PMid:33619379

41. Albhaisi SA, Bajaj JS, Sanyal AJ. Role of gut microbiota in liver disease. Am J Physiol Gastrointest Liver Physiol. 2020;318(1):G84-98. https://doi.org/10.1152/ajpgi.00118.2019 PMid:31657225

42. Kirpich IA, Solovieva NV, Leikhter SN, Shidakova NA, Lebedeva OV, Sidorov PI, et al. Probiotics restore bowel flora and improve liver enzymes in human alcohol-induced liver injury: A pilot study. Alcohol. 2008;42(8):675-82. https://doi. org/10.1016/j.alcohol.2008.08.006

PMid:19038698

43. Gao X, Zhu Y, Wen Y, Liu G, Wan C. Efficacy of probiotics in non-alcoholic fatty liver disease in adult and children:
A meta-analysis of randomized controlled trials. Hepatol Res. 2016;46(12):1226-33. https://doi.org/10.1111/hepr.12671.

PMid:26866817

44. Sproston NR, Ashworth JJ. Role of C-reactive protein at sites of inflammation and infection. Front Immunol. 2018;9:754. https:// doi.org/10.3389/fimmu.2018.00754.

PMid:29706967

45. Rajkumar H, Mahmood N, Kumar M, Varikuti SR, Challa HR, Myakala SP. Effect of probiotic (VSL\#3) and omega-3 on lipid profile, insulin sensitivity, inflammatory markers, and gut colonization in overweight adults: A randomized, controlled trial. Mediators Inflamm. 2014;2014:348959. https://doi. org/10.1155/2014/348959

PMid:24795503

46. Mazidi M, Rezaie P, Ferns GA, Vatanparast H. Impact of probiotic administration on serum C-reactive protein concentrations: Systematic review and meta-analysis of randomized control trials. Nutrients. 2017;9(1):20. https://doi.org/10.3390/ nu9010020

PMid:28054937 